\title{
Knowledge and Awareness of Breast Self-Examination among Secondary School Girls in Seremban, Negeri Sembilan
}

\author{
Nur Anis Izzati Che Mut ${ }^{1}$, Noor Hidayah Abu Bakar', Izdihar Kamal', Siti \\ Aisyah Abdullah Suhaimi ${ }^{1}$, Nurul Mawaddah Mohammad ${ }^{1}$, Rosmah Ahmad ${ }^{2}$, \\ Norhayati Mohd Zain ${ }^{1}$
}

${ }^{1}$ Medical Imaging Department, School of Health Sciences, KPJ Healthcare University College, N. Sembilan, Malaysia. ${ }^{2}$ Department of Student Affairs, KPJ Healthcare University College, Negeri Sembilan, Malaysia.

\begin{abstract}
Objective: Breast Self-Examination (BSE) is an early detection method of breast cancer. It is able to develop responsibility for breast health among women to always aware of any changes in the breast. Thus, secondary school girls age is the perfect age to start practice the BSE. The purpose of this study is to determine the level of knowledge and awareness on BSE among secondary school girls in Seremban, Negeri Sembilan. Methods: A cross-sectional study was conducted among 502 secondary school girls using self-administered questionnaire covering socio-demographic data, knowledge and awareness of breast cancer and knowledge and awareness of BSE. Results: The mean age of the participants is $14.9 \pm 0.06$ years. The majority of the participants were Malays $(86.5 \%)$. A total of $6.1 \%$ of the participants had a family history of breast cancer. Nine percent of participants had a good knowledge and $91.0 \%$ had poor knowledge regarding BSE. There is a significant difference between the age of participants with the level of knowledge and awareness $(\mathrm{p}=0.014)$. Conclusion: The knowledge and awareness of BSE were poor among secondary school girls in Seremban, Negeri Sembilan.
\end{abstract}

Keywords: Breast Self- examination- knowledge- awareness- school girls

Asian Pac J Cancer Care, 4 (2), 39-43

\section{Introduction}

Most breast cancers occur in older women [1] where the rates of breast cancer increased on age of 40 and highest in women in age of 50 to 59 [2] however incidence rate for breast cancer among all adolescents and young adults increased rapidly between 15 and 39 years of age [3]. Young women who developed invasive breast cancer experienced greater absolute and relative functional losses in physical role function, bodily pain, social function, and mental health compared with middle age or elderly women with the incident of breast cancer [4]. Therefore, early detection of breast cancer plays the leading role in reducing mortality rates and improving patient's prognosis [5].

Breast Self-Examination (BSE) is a self-inspection technique where women will examine their own breasts by observing and palpating with their fingers to detect any
Submission Date: 12/11/2018 Acceptance Date: 02/07/2019

abnormal changes and lumps. It is a monthly examination of the breast by women at the end of menstrual flow [6]. It is an important screening tool for early detection of breast cancer because it is cheap, widely available and does not require complex technical training [7]. It also enhances the sensitivity and alert on abnormal changes at earliest, so that women are aware of any breasts changes detected during BSE [8]. Additionally, by performing regular BSE, it is able to empower women and encourage them to take responsibility for their own health. Thus, it is recommended for raising women's awareness of the importance of BSE.

However, they believes that they had very little chance of being diagnosed with breast cancer [9] and the finding of research that breast cancer commonly happened in women age 40 years old and above make the young women ignore this issues and not aware of the signs and symptoms such as breast characteristic changes.

Corresponding Author:

Dr. Norhayati Mohd Zain

Medical Imaging Department, School of Health Sciences, KPJ Healthcare University College, N. Sembilan, Malaysia.

Email: norhayati@kpjuc.edu.my 
This is happened due to the lack of knowledge of breast cancer among young women [10-11]. Furthermore, most young women had a low level of knowledge in relation to BSE [12-13].

Although there were a lot of studies about the knowledge and awareness of BSE among female university students there are limited studies on secondary school girls. Therefore, this study was conducted among secondary school girls to determine the level of knowledge and awareness on BSE, to compare the level of knowledge and awareness on BSE between age group and to correlate the level of knowledge and awareness on BSE with age among secondary school girls in Seremban, Negeri Sembilan.

\section{Materials and Methods}

\section{Study design and population}

A cross-sectional study was conducted from February 2018 to July 2018 at five selected secondary schools in Seremban, Negeri Sembilan. 502 female students were recruited from age 13,14 and 16 years old. Age 15 and 17 years old were excluded from the sampling frame in order to obey the rule from Ministry of Education Malaysia. Informed consent was obtained from all the participants.

\section{Data collection}

Each participant was given a set of validated questionnaire to answer. The questionnaire was designed to obtain information on socio-demographic data, knowledge and awareness of breast cancer and knowledge and awareness of BSE. It was developed based on information drawn from previous literature. A yes and no format answer was used on knowledge and awareness of breast cancer and BSE. The questionnaire was developed in Bahasa Malaysia, then translated into English. The translation was validated by an expert. The questionnaire was pre-test on 30 secondary female girls which not included in the final sample with the section regarding knowledge on breast cancer with

$\alpha=0.85$ and section regarding knowledge on BSE with $\alpha=0.79$. In addition to questions on socio-demographic data (age, race, father's and mother's education and occupation, family history of breast cancer), the final instrument had 26 items where it covered general knowledge of breast cancer and BSE, sign and symptoms of breast cancer, risk factors of breast cancer, screening of breast cancer and practice of BSE.

\section{Ethical consideration}

Permission was obtained from Ethical Review Board of KPJ Healthcare University College (KPJUC/RMC/EC/2018/121), Ministry of Education Malaysia [KPM.600-3/2/2-eras(115)] and the state education department [JPNS.SPS.PP.100-1/7 Jld.17(19)] to carry out this study in 5 selected secondary schools in Seremban, Negeri Sembilan.

\section{Statistical analysis}

All data were analysed using the Statistical Package for the Social Sciences (SPSS Inc., Chicago, IL) version 23.0 and Microsoft Excel. Categorical response (Yes/No/Don't know) was applied for the question items. A score of 2 was assigned to each yes and correct answer, 1 to each not sure or don't know answer while zero was assigned to no and incorrect answers. For knowledge and awareness of breast cancer, the total score was 52. By referring to the expert, a score of $0-42$ was considered poor knowledge and 43-52 was considered good knowledge. The total score of knowledge and awareness of BSE was 62. A score of 0-34 was considered poor knowledge and 35-62 was considered as good knowledge. Descriptive analysis was used to determine the level of knowledge and awareness on BSE, ANOVA test was used to compare the level of knowledge and awareness on BSE between age and correlation was used to correlate the level of knowledge and awareness of BSE with age.

\section{Results}

A total of 502 questionnaires were fully completed. Table 1 shows the socio-demographic data of the participants. The age of the participants is from 13, 14 and 16 years old with the mean age of $14.99 \pm 0.056$. Overall, the majority of the participants, 437 (86.5\%) were Malays, 48 (9.5\%) were Indians, $14(2.8 \%)$ were Chinese and $3(0.6 \%)$ were the others. Only $31(6.1 \%)$ out of the participants had a family history of breast cancer.

Knowledge regarding breast cancer is shown in Table 2. The knowledge of breast cancer among participants was poor with only $8(1.6 \%)$ had good knowledge regarding breast cancer. Most of the participants had little knowledge of the risk factors of breast cancer. The most widely known risk factors by the participants were having a family history of breast cancer (40.8\%) and followed by increasing the age $(24.4 \%)$. However, important risk factors such as usage of contraceptive pills never had a child and obesity were less known by participants as the risk factors of breast cancer. Most of the participants $(29.7 \%)$ did not know the early detection method for breast cancer.

Table 3 shows the participants' knowledge regarding BSE. The knowledge and awareness of BSE among participants were poor with only $45(9.0 \%)$ of participants had a good knowledge while about 457 (91.0\%) had poor knowledge regarding BSE. More than half of the participants $(53.0 \%)$ did not know about BSE. However, the majority of the participants $(62.9 \%)$ knew that BSE is an early detection technique for breast cancer. Health campaign was identified as the main source of information regarding BSE by $56.6 \%$ of the participants, followed by mass media and books and journals.

Most of the participants (76.3\%) have never been taught the correct way on performing BSE. Out of the participants that been taught the correct way in performing BSE, the majority said doctors played important role in teaching them the BSE (16.3\%) and followed by nurses $(13.5 \%)$. The knowledge regarding BSE is poor among the participants which only $3.2 \%$ knew the age recommended for BSE practices and only $12.7 \%$ knew the appropriate 
Table 1. Socio-demographic Data $(n=502)$

\begin{tabular}{|c|c|c|}
\hline Socio-demographic & Frequency & Percentage $(\%)$ \\
\hline \multicolumn{3}{|l|}{ Age (years old) } \\
\hline 13 & 99 & 19.6 \\
\hline 14 & 105 & 20.8 \\
\hline 16 & 298 & 59.0 \\
\hline \multicolumn{3}{|l|}{ Race } \\
\hline Malay & 437 & 86.5 \\
\hline Chinese & 14 & 2.8 \\
\hline Indian & 48 & 9.5 \\
\hline Others & 3 & 0.6 \\
\hline \multicolumn{3}{|l|}{ Father's education } \\
\hline Primary school & 18 & 3.6 \\
\hline Secondary school & 224 & 44.4 \\
\hline Diploma holder & 153 & 30.3 \\
\hline Bachelor Degree & 67 & 13.3 \\
\hline Master Degree & 29 & 5.7 \\
\hline Ph.D. holder & 11 & 2.2 \\
\hline \multicolumn{3}{|l|}{ Father's occupation } \\
\hline Government sector & 123 & 24.4 \\
\hline Private sector & 227 & 45.0 \\
\hline Self-Employed & 132 & 26.1 \\
\hline Not/ Has not been employed & 20 & 4.0 \\
\hline \multicolumn{3}{|l|}{ Mother's education } \\
\hline Primary school & 34 & 6.7 \\
\hline Secondary school & 247 & 48.9 \\
\hline Diploma holder & 136 & 26.9 \\
\hline Bachelor Degree & 53 & 10.5 \\
\hline Master Degree & 23 & 4.6 \\
\hline Ph.D. holder & 9 & 1.8 \\
\hline \multicolumn{3}{|l|}{ Mother's occupation } \\
\hline Government sector & 127 & 25.1 \\
\hline Private sector & 91 & 18.0 \\
\hline Self-Employed & 92 & 18.2 \\
\hline Not/ Has not been employed & 192 & 38.0 \\
\hline \multicolumn{3}{|l|}{ Family history of breast cancer } \\
\hline Yes & 31 & 6.1 \\
\hline No & 471 & 93.3 \\
\hline
\end{tabular}

time for practicing BSE. The percentage of the participants who had the knowledge to perform BSE was only $21.1 \%$.

Table 4 shows the sign and symptoms of breast cancer that needs to give attention while performing BSE. Most of the participants had little knowledge on sign and symptoms of breast cancer. The most widely known by the participants were a lump in the breast $(71.5 \%)$, followed by a sudden discharge from the nipple (70.7\%) and a reddish swollen breast $(70.5 \%)$. However, changes in the skin colour of the breast, an inserted nipple and wrinkles around the breast were not known as sign and symptoms to be given attention while performing BSE. However, the majority of participants $(82.8 \%)$ were aware that BSE is important as an early measure to prevent breast cancer.

The comparison between the level of knowledge and awareness on BSE and age group of participants is shown in Table 5. ANOVA test showed that there was a significant difference in knowledge and awareness of BSE among age group $(p=0.014)$. Age and the level of knowledge and awareness on BSE have no statistically significant linear relationship $(\mathrm{p}=0.072)$.

\section{Discussion}

Early detection of breast cancer plays an important role in reducing breast cancer mortalities. Developing a good health practice should be started from an early age as this can develop a good healthy attitude. . Thus, school-age girls are fit for the target for early exposure regarding knowledge of breast cancer and early detection method of breast cancer.

In this study, the majority of the participants $(91.0 \%)$ had poor knowledge regarding BSE. This is because most of the participants $(53.0 \%)$ stated that they did not know about BSE. This showed that BSE is not well known among young females due to poor health behaviour and attitudes regarding breast cancer. Similar findings found in the previous study done in Turkey, the study showed that young females in Turkey did not have sufficient knowledge about BSE, where only $13.2 \%$ knew the appropriate time for BSE, $21.8 \%$ knew the frequency of BSE and $26.6 \%$ knew the procedure of BSE [14]. This is consistent with a study conducted in Malaysia where less than $1 \%$ of the participants had very good knowledge and more than $30 \%$ of the study population had poor to very poor knowledge [10].

The majority of the participants $(93.9 \%)$ had no family history of breast cancer. This might be the reason that contributes to the high number of participants with poor knowledge of BSE. The family history of breast cancer is one of the risk factors for breast cancer [15]. However, according to American Cancer Society (2015), the majority of women with the first-degree relative with breast cancer will never develop breast cancer while most of the women with no family history of the disease will develop them. This is because women with a family

Table 2. Knowledge on Breast Cancer

\begin{tabular}{lc}
\hline Knowledge regarding breast cancer & $\mathrm{n}(\%)$ \\
\hline Knowledge on breast cancer & $8(1.6)$ \\
$\quad$ Good & $494(98.4)$ \\
Poor & \\
Risk factors of breast cancer & $206(40.8)$ \\
$\quad$ Having family history of breast cancer & $42(8.3)$ \\
Never had a child & $107(21.2)$ \\
Never breastfeeding & $67(13.3)$ \\
Usage of contraceptive pills & $72(14.3)$ \\
Obesity & $123(24.4)$ \\
Increasing of age & \\
Knowledge on early detection of breast cancer & \\
Yes & $353(29.7)$ \\
No &
\end{tabular}


Table 3. Knowledge of BSE

\begin{tabular}{lc}
\hline Knowledge regarding BSE & $\mathrm{n}(\%)$ \\
\hline Knowledge of BSE & $45(9.0)$ \\
Good & $457(91.0)$ \\
Poor & \\
Know about BSE & $236(47.0)$ \\
Yes & $266(53.0)$ \\
No & \\
Knowledge on appropriate time for BSE & $64(12.7)$ \\
Correct answer & $36(7.2)$ \\
Wrong answer & $402(80.1)$ \\
Not sure & \\
Knowledge on appropriate age for BSE & $16(3.2)$ \\
Correct answer & $176(35.1)$ \\
Wrong answer & $310(61.8)$ \\
Not sure & \\
Knowledge on BSE procedure & $106(21.1)$ \\
Yes & $396(78.9)$ \\
No & \\
Source of information regarding BSE & $284(56.6)$ \\
Health campaign & $257(51.2)$ \\
Mass Media & $202(40.2)$ \\
Books and journals & $187(37.3)$ \\
Parents & $123(24.5)$ \\
Friends &
\end{tabular}

history of breast cancer were more likely to adhere to breast cancer examinations [16]. This is supported by a study by Haber et al., (2012) that women with positive family history held higher risk perception levels and the high repeat of breast screening. This showed that the women with positive family history of breast cancer had greater awareness about the disease as they witnessed what their family have been through.

The knowledge of risk factors of breast cancer is poor, where only $8.3 \%$ and $13.3 \%$ of the participants knew that never had a child and the usage of contraceptive pills are one of the risk factors of breast cancer. This is due to they were still in the school age group and the majority of them (79.9\%) were not exposed to the general knowledge of breast cancer. This demonstrates that education and early exposure to breast disease are important to them.

Table 4. Sign and Symptoms to be Paid Attention while Performing BSE $(\mathrm{n}=502)$

\begin{tabular}{lc}
\hline Sign and symptoms & $\mathrm{n}(\%)$ \\
\hline Change in the size and shape of the breast & $340(67.7)$ \\
Changes in the skin colour of the breast & $225(44.8)$ \\
A sudden discharge from the nipple & $355(70.7)$ \\
A reddish swollen breast & $354(70.5)$ \\
A lump on the breast & $359(71.5)$ \\
Wrinkles around the breast & $248(49.4)$ \\
An inserted nipple & $241(48.0)$ \\
\hline
\end{tabular}

Table 5. Level of Knowledge and Awareness on BSE According to Age

\begin{tabular}{llc}
\hline Age (years old) & Mean (SD) & p-value \\
\hline 13 & $18.2(9.07)$ & $\mathrm{p}=0.014$ \\
14 & $22.0(9.78)$ & \\
16 & $21.3(10.47)$ & \\
\hline
\end{tabular}

ANOVA, two sided $P$ value $<0.05$

The findings are similar to the study in Riyadh City among female high school students, which only $58.5 \%$ knew that usage of contraceptive pills is one of the risk factors [17]. However, in this study, the most widely known risk factor of breast cancer is a family history of breast cancer $(40.8 \%)$ and increasing of age $(24.4 \%)$. This is due to information which always been circulated in media and community.

Same goes to the sign and symptoms that need to pay attention while performing BSE which have a low percentage $(44.8 \%)$ of participants who know about the changes in skin colour of breast and $48.0 \%$ on the inserted nipple. This is similar to the study in Malaysia among undergraduate female students, where only $25.8 \%$ knew about nipple retraction is a risk factor of breast cancer [13]. This reflects that the knowledge regarding sign and symptoms of breast cancer is poor among the participants.

Our findings showed that health campaign $(56.6 \%)$ and mass media $(51.2 \%)$ were the main sources of information for BSE. These findings clearly showed that health campaign and mass media were able to give information regarding BSE to the participants. Similar findings by Akhtari-Zavare et al. (2013) stated that radio and television were the main sources of information for breast cancer and BSE practice among female students at University Putra Malaysia. This is supported by the study in the University of Buea, where television (19.9\%) was the most widely chosen source of information by the participants [18].This showed that the media plays a vital role in giving information for the young females as it is presented accessibly and nicely attracts the youth [19].

The relationship between the age of the participants and the level of knowledge and awareness regarding BSE showed that there was a significantly different $(p=0.014)$. The mean of knowledge increases with age indicates that there was higher knowledge regarding BSE in the participants with age of 14 and 16 years old compared to 13 years old. This is supported by the study in by Nde et.al (2015) that stated that age did have a significant effect on the knowledge of BSE. Increasing in the age of women will increase the level of knowledge and awareness of BSE. This is due to facts that most girls' breasts development begin with breast budding around the age of 9 and it continues to fully develop around the age of 17 [20]. Thus, this will increase the awareness of breast health among the girls. However, there is no significant linear relationship between age and level of knowledge and awareness of BSE $(p=0.072)$. This showed that the level of knowledge and awareness regarding BSE between the participants have no large difference despite having 
a different age.

In conclusion, the findings of this study are in keeping with previous studies in which the knowledge and awareness of BSE were found to be poor among secondary school girls in Seremban, Negeri Sembilan, however, there is the significant difference between the different ages. Therefore, an educational intervention program is necessary to improve the knowledge and awareness about BSE among secondary school girls. In order to improve knowledge and awareness of BSE, it is important to initiate an educational intervention program to provide an early exposure on BSE and to develop positive health behaviour on the breast at the early age.

\section{Acknowledgments}

The authors would like to express their sincere gratitude to Ministry of Education Malaysia, State Education Department of Negeri Sembilan, Sekolah Menengah Kebangsaan Seremban 3, Sekolah Menengah Kebangsaan Senawang, Sekolah Menengah Kebangsaan King George V, Sekolah Menengah Kebangsaan Desa Cempaka, Sekolah Menengah Kebangsaan Bandar Enstek and all who have contributed to this study formal and informally. This work supported in part by KPJ Healthcare University College.

\section{References}

1. McPherson K, Steel CM, Dixon JM. ABC of breast diseases. Breast cancer-epidemiology, risk factors, and genetics. BMJ (Clinical research ed). 2000;321(7261):624-8.

2. Omar ZA MAZ, Ibrahim Tamin NS Malaysian Cancer Statistics - Data and Figure Peninsular Malaysia 2006, Female Breast (ICD): C50), National Cancer Registry, Ministry of Health Malaysia, Malaysia, (2006). . pp 78-9. p.

3. Keegan TH, DeRouen MC, Press DJ, Kurian AW, Clarke CA. Occurrence of breast cancer subtypes in adolescent and young adult women. Breast cancer research : BCR. 2012;14(2):R55.

4. Kroenke CH, Rosner B, Chen WY, Kawachi I, Colditz GA, Holmes MD. Functional impact of breast cancer by age at diagnosis. Journal of clinical oncology : official journal of the American Society of Clinical Oncology. 2004;22(10):184956.

5. Elmore JG, Armstrong K, Lehman CD, Fletcher SW. Screening for breast cancer. Jama. 2005;293(10):1245-56.

6. Baxter N. Preventive health care, 2001 update: should women be routinely taught breast self-examination to screen for breast cancer? CMAJ : Canadian Medical Association journal $=$ journal de l'Association medicale canadienne. 2001;164(13):1837-46.

7. Babu GR, Samari G, Cohen SP, Mahapatra T, Wahbe RM, Mermash S, et al. Breast cancer screening among females in Iran and recommendations for improved practice: a review. Asian Pacific journal of cancer prevention : APJCP. 2011;12(7):1647-55.

8. Thomas DB, Gao DL, Ray RM, Wang WW, Allison CJ, Chen FL, et al. Randomized trial of breast self-examination in Shanghai: final results. Journal of the National Cancer Institute. 2002;94(19):1445-57.

9. Johnson N D-SV. It usually happens in older women': Young women's perceptions about breast cancer. . "Health
Education Journal. (2008);67, :243-57.

10. Hadi MA, Hassali MA, Shafie AA, Awaisu A. Evaluation of breast cancer awareness among female university students in Malaysia. Pharmacy practice. 2010;8(1):29-34.

11. Ranasinghe HM, Ranasinghe N, Rodrigo C, Seneviratne Rde A, Rajapakse S. Awareness of breast cancer among adolescent girls in Colombo, Sri Lanka: a school based study. BMC public health. 2013;13:1209.

12. Doshi D, Reddy BS, Kulkarni S, Karunakar P. Breast Selfexamination: Knowledge, Attitude, and Practice among Female Dental Students in Hyderabad City, India. Indian journal of palliative care. 2012;18(1):68-73.

13. Akhtari-Zavare M, Juni MH, Ismail IZ, Said SM, Latiff LA. Barriers to breast self examination practice among Malaysian female students: a cross sectional study. SpringerPlus. 2015;4:1-6.

14. Karayurt O, Ozmen D, Cetinkaya AC. Awareness of breast cancer risk factors and practice of breast self examination among high school students in Turkey. BMC public health. 2008;8:1-8

15. Brewer HR, Jones ME, Schoemaker MJ, Ashworth A, Swerdlow AJ. Family history and risk of breast cancer: an analysis accounting for family structure. Breast cancer research and treatment. 2017;165(1):193-200.

16. Shah M, Zhu K, Palmer RC, Jatoi I, Shriver C, Wu H. Breast, colorectal, and skin cancer screening practices and family history of cancer in U.S. women. Journal of women's health (2002). 2007;16(4):526-34.

17. KM. A-H, SA. M. Breast cancer, Breast Self-Examination Knowledge Among Female High School Students in Riyadh City.(2015). . 25-7. p.

18. Nde FP, Assob JC, Kwenti TE, Njunda AL, Tainenbe TR. Knowledge, attitude and practice of breast self-examination among female undergraduate students in the University of Buea. BMC research notes. 2015;8:1-6.

19. O F. Positive and negative influences of the mass media upon education. (2014). . 349-53. p.

20. Kelsey BM N-RJ. Midwifery \& women's health nurse practitioner certification review guide, Normal Gynecology and Well-Women Care: Reproductive Years, Jones \& Bartlett Learning, Burlington, pp 37. (Internet). (2018).

\section{(i) (8)}

This work is licensed under a Creative Commons AttributionNon Commercial 4.0 International License. 